\title{
Linguistic Relativity from Reference to Agency
}

\author{
N.J. Enfield
}

The University of Sydney, Department of Linguistics, NSW 2006, Australia; email: nick.enfield@sydney.edu.au

Max Planck Institute for Psycholinguistics, 6500 AH Nijmegen, The Netherlands

Annu. Rev. Anthropol. 2015. 44:207-24

The Annual Review of Anthropology is online at anthro.annualreviews.org

This article's doi:

10.1146/annurev-anthro-102214-014053

Copyright (c) 2015 by Annual Reviews. All rights reserved

\section{Keywords}

language and thought, categorization, Whorf, agency, accountability, functions of language, social reality, linguistic relativity

\begin{abstract}
How are language, thought, and reality related? Interdisciplinary research on this question over the past two decades has made significant progress. Most of the work has been Neo-Whorfian in two senses: One, it has been driven by research questions that were articulated most explicitly and most famously by the linguistic anthropologist Benjamin Lee Whorf, and two, it has limited the scope of inquiry to Whorf's narrow interpretations of the key terms "language," "thought," and "reality." This article first reviews some of the ideas and results of Neo-Whorfian work, concentrating on the special role of linguistic categorization in heuristic decision making. It then considers new and potential directions in work on linguistic relativity, taken broadly to mean the ways in which the perspective offered by a given language can affect thought (or mind) and reality. New lines of work must reconsider the idea of linguistic relativity by exploring the range of available interpretations of the key terms: in particular, "language" beyond reference, "thought" beyond nonsocial processing, and "reality" beyond brute, nonsocial facts.
\end{abstract}




\section{EFFECTS OF LINGUISTIC CATEGORIZATION}

In April 1985, Texas Tech University student and rape victim Michele Mallin mistakenly identified 26-year-old Timothy Cole as her attacker, first from a photograph, then in a police lineup. Cole would later die in prison after serving 13 years of a 25 -year sentence for a crime he did not commit (see http://www.innocenceproject.org/Content/Timothy_Cole.php). Many factors are known to contribute to such unthinkable distortions of memory, but one may seem surprising: the role of language. The science of memory has shown that if we verbally describe something we have seen, as when a victim describes an attacker to police, this act of putting experience into words can overshadow our exact recollection of the original experience (Schooler \& Engstler-Schooler 1990; see also Loftus \& Palmer 1974, Lupyan 2008). ${ }^{1}$ By verbalizing something, we can become more likely to make a wrong decision on the basis of what we said we saw (and now believe we saw). Schooler \& Engstler-Schooler (1990) discovered this effect in relation to how people remember faces: If we see a face and then describe it in words, we will later be worse at recognizing it than if we had not verbally described it at all. They also found that committing perceptions to words can make memory worse for another perceptual domain: color. In an experiment, they showed people a set of subtly different hues. Some were asked to describe the colors in words. These people were worse at later identifying the exact color they had seen. Those who had not verbally described the original color, on the other hand, were better at remembering it. By saying what they saw, those in the first group were allowing language to deplete or alter their mental representation of the original experience. This happens with faces and colors because they are domains that “defy linguistic description" (Schooler \& Engstler-Schooler 1990, p. 66)—no language makes distinctions among faces or colors anywhere near as finely as our visual discrimination can. The authors concluded that "[s]ome things are better left unsaid" (p. 67).

How is it that recounting an experience in words can cause a distortion of memory? This effect of language on cognition is a by-product of an otherwise critical function of language: categorization. To categorize things is to group them together, treating them as effectively identical for some purpose by disregarding or discarding irrelevant differences (Cohen \& Lefebvre 2005, Levinson $\&$ Majid 2014). Language is centrally involved. The concepts that words encode are ready-at-hand devices for categorizing (Taylor 2004, Enfield 2015). So, for example, even though no two fish are the same, we treat them as the same when we refer to them both with a single word fish. Of course the person who says I caught two fish today should know whether they were the same or different species, but their addressee cannot know just from hearing the phrase two fish. Linguistic categorization omits distinguishing information. Now because we know that the meanings of words differ greatly across languages \{see semanticists from Boas [1966 (1911)] to Goddard \& Wierzbicka (2014)\}, the information omitted in any verbal act of categorization must be different in different languages. English does not put a sturgeon and a dolphin in the same basic-level category, but many other languages do. In Lao, the word paa covers fish and dolphins in a single concept (Kerr 1972, p. 591). A comparison of any two languages will quickly yield thousands of examples such as this (see Bowerman \& Levinson 2001, Gentner \& Goldin-Meadow 2003, Evans 2010b, Malt \& Wolff 2010, Riemer 2010, inter alia).

The trusted concepts that words and other linguistic symbols provide give our minds ways to economize by omitting needless detail. We may save on mental processing, for example, by not having to remember a particular fish's irrelevant peculiarities once we have classified it as a fish. The trade-off, as the research on overshadowing shows, is that we may lose later access

\footnotetext{
${ }^{1}$ It is not known if language was a factor in Tim Cole's misidentification, but the overshadowing research gives us every reason to think that it was.
} 
to context-specific details that we could have otherwise stored. On balance, the trade-off is good. Most of the time we do not need the details. But once in a while details turn out to be indispensable. We learn this if we find ourselves buying the wrong tint of paint for the house or, more consequentially, convicting an innocent man.

\section{WHORFIANISM}

If language can imperceptibly constrain or channel our thoughts in ways like this, it raises a counterintuitive challenge to our sense of free will. Do our trains of thought run on tracks laid by language, such that each different language takes our thoughts to a different place? A lineage of language scientists has posed and explored these questions, from Herder (1992) in the eighteenth century and von Humboldt [1988 (1836)] in the nineteenth, to Boas [1966 (1911)] and Sapir (1949) in the twentieth century and even more recently (see Leavitt 2010). Perhaps the best-known author to pose this question is the anthropological linguist Benjamin Lee Whorf (see Whorf 2012).

Whorf's considerable accomplishments in Native American and Mesoamerican linguistics, including his 1930s fieldwork on the Aztec language and his contributions to the decipherment of Mayan hieroglyphs, are still referenced in specialist literature of that area. In linguistics more generally, Whorf made lasting contributions to the study of how meaning is encoded, both overtly and covertly, in grammatical systems. But Whorf is discussed most for his proposals concerning relations between language, thought, and reality. In a short article written in 1939, titled "The Relation of Habitual Thought and Behavior to Language," Whorf considered the possible role of language in human error leading to accidental fires, drawing on his professional experience as an insurance investigator (see Whorf 2012, pp. 173-204). What he pointed to was not unlike the verbal overshadowing effect for faces and colors. In line with previous proposals by Boas and Sapir, Whorf argued that a linguistically grounded habit of thinking might play a causal role in nonlinguistic behavior. In one of his fire insurance examples, an explosion occurred when workers were careless with cigarettes near empty gasoline drums. Whorf reasoned that if an English speaker thinks of a gasoline drum as empty because there is no gasoline in it, this use of the English word empty suggests to the person that there is literally nothing in the drum. Hence the person ignores the possibility that the drum is, in fact, full of vaporous fumes, and hence the dangerous behavior.

If you think this means Whorf was taking language to be the sole determinant of behavior, or even a straitjacket for thought, you would not be alone. But Whorf never said these things nor did he think them. Presenting his case in the "condensed and unqualified form" required for that short article, he had hoped the reader "would use his thinking apparatus" and adjust accordingly (these quotations from a letter to his editor cited in Lee 1996, p. 153). In response to his editor's suggestion that he may have overemphasized the role of language in channeling behavior, Whorf explained,

I have thought of possibly adding a brief statement or a footnote saying that I don't wish to imply that language is the sole or even the leading factor in the types of behavior mentioned such as the fire-causing carelessness through misunderstandings induced by language, but that this is simply a coordinate factor along with others. It didn't seem at first that this should be necessary if the reader uses ordinary common sense. (Lee 1996, p. 153)

Here is what Whorf suggested. When deciding how to behave, one might naturally use language in thinking, and in so doing one may effectively discard, or fail to notice, important information that happens not to feature in a linguistic rendering of the state of affairs at hand. It is not that people cannot comprehend alternative depictions of reality. Nor is it that we cannot think without 
language. It is that we are creatures of habit. If language is our most practiced resource, it should be no surprise that language instills deep cognitive habits: habits of attention and disattention, habits of reasoning — or failing to reason-in deciding how to act.

\section{HEURISTIC THINKING}

A common gloss of Whorf's view is that a language will predispose us to think certain things. But we could just as well—or better-say that a language predisposes us not to think certain things. The fact that people fail to notice much of what goes on around us is now well established (Grimes 1996, Simons \& Levin 1997). Research on rational heuristics in decision making shows that to routinely disregard a portion of the available information not only is a common strategy, but in fact makes good sense (Gigerenzer et al. 2011). The logic of decision making includes a desire to minimize the costs involved. It is the same from small things, such as choosing which brand of cigarettes to buy, to big things, such as finding a marriage partner. Once you have locked on to the problem (e.g., Which one to choose?), your next step is to find ways to narrow the search for an appropriate solution and "lock off" by making the decision that yields the best balance: desired benefit for lowest cost. And a decision should be made without unnecessary delay in order to get on with solving the next puzzle in the stack.

Take a simple decision such as choosing what to order at a restaurant. One strategy would be to study the entire menu and weigh all the options, comparing them on some criteria and selecting the best. But such thoroughness could be cognitively and socially costly and a waste of time. A good alternative is the strategy known as satisficing (Simon 1956, 1983; compare Gigerenzer 2007, Kahneman 2011): Do not waste your time studying all the options; simply settle on the first solution that is good enough for current purposes and stop the search. So, if you already like the idea of the mushroom risotto, it may not pay to keep looking at the menu in the hope of finding something better.

How do we determine what qualifies as good enough? One way is to use concepts. Concepts are tools in decision making because they give us criteria for recognizing instances of what we are looking for and of what we are not looking for. In this way, concepts are sieves (Kockelman 2013; Enfield 2015, p. 172). They are means for deciding, and thus for acting. Whorf's idea was simply that language is likely to play a central role in decision making along these lines. At the root of this idea are two facts: (a) the most ready-at-hand concepts are the ones encoded in the languages we speak, ${ }^{2}$ and $(b)$ the languages we speak are known to differ radically in the kinds of concepts they encode. This suggests a prima facie argument for a form of cultural relativity grounded in differences between languages. If concepts provide a basis for categorization and decision making, and if different languages supply their speakers with different concepts, then different languages provide their speakers with different bases for decision making and, subsequently, for different patterns of behavior.

Some may recoil at the idea of relativity (or relativism) in any form, appealing to common sense. Philosopher Paul Boghossian opens his antirelativist book Fear of Knowledge with a controversy surrounding Native American origins (Boghossian 2006). Although many archaeologists believe that humans migrated ten millennia ago from Asia into America via the Bering Strait, some Native Americans believe that their people emerged onto the Earth from a subterranean spirit world. These two versions of reality are, of course, not equally valid (or at least not valid in the same

${ }^{2}$ Of special interest for Whorf and many since was the encoding of concepts in grammatical as opposed to lexical forms, given that the former are maximally requisite, tacit, and practiced, and thus maximally habitual. 
way). There are facts that do not stop being facts just because we believe something else. Rocks will sink, whether you like it or not. But there are other versions of relativity than those grounded in a refusal to acknowledge brute facts. A version of relativity more likely to succeed begins with the observation that we cannot determine facts independently from the measuring instruments that are used. Our primary measuring instruments are our bodies (Gibson 1979, Ingold 2000). Why can dogs hear sounds we cannot? Because dogs have different bodies than we do. For humans with human ears, ultrasonic noises may as well not be real (although we can infer their existence using other means, from hi-tech instruments such as spectrograms to low-tech measures such as visual observations of dogs' behaviors). The body defines an individual's horizons, both limiting and licensing our possible perceptions and actions. If you have the body of a bat, a pitch-dark cave will seem like a good place to be. With the body of an earthworm you will feel at home in a stretch of turf. If these are not different worlds, they are certainly different worldviews.

Along similar lines, each language is a kind of body for thinking and acting. Philosopher of mind Gilbert Ryle advocated a view of cognition as a public phenomenon, defining it not by putative internal states but by the "assemblage of performances" that such states enable (Ryle 1949, p. 45; Enfield 2013, p. 58). To perceive or understand the world is to relate to it, interpret it, and react to it. The reasoning involved draws on concepts and categories in a range of ways, and, as is clear to anyone who looks, many if not most of our concepts and categories are supplied by the languages we speak.

This is pretty much what Whorf and his predecessors were suggesting. As Edward Sapir, Whorf's teacher at Yale, wrote, "[T]he language habits of our community predispose certain choices of interpretation" (Sapir 1949, p. 162). On this view, the study of different languages, especially of those that are most different from so-called Standard Average European (Whorf 2012, p. 358), has the potential to supply us with new and different ways of actively interpreting the world. Whorf avidly promoted the study of lesser-known languages, such as those of Native America, because each provides an opportunity to broaden our understanding in one more way. Although nobody is "free to describe nature with absolute impartiality," Whorf argued, the person who would come closest "would be a linguist familiar with very many widely different linguistic systems" (Whorf 2012, p. 274). Today's language explorers are fulfilling this ambition. As Evans (2010a, p. 155) writes, "we study other languages because we cannot live enough lives."3

\section{NEO-WHORFIANISM}

How are we to treat Whorf's idea today, some 75 years later? Some have taken it to be no more than a suggestive framework, serving as a conceptual guide for anthropological research or as a source of hypotheses for experimental testing (see Gumperz \& Levinson 1996, Gentner \& Goldin-Meadow 2003). Others have pressed too hard on the idea, dismissing it for its failure to take the weight (McWhorter 2014). But it is not clear that Whorf's work was designed to bear that load. Nor are people always critiquing the thing that Whorf actually proposed. Cognitive anthropologist Stephen C. Levinson describes the problem: "It is as if the topic of 'Whorfianism' is a domain where anybody can let off steam, go on mental holiday, or pounce upon an ideological enemy" (Levinson 2003a, p. 25). Whorf commentator Penny Lee counts the ways Whorf has been "misread, unread, and superficially treated" (Lee 1996, p. 14; see also Levinson 2012, p. xiii, footnote 3).

\footnotetext{
${ }^{3}$ These words are adapted by Evans from those of literary critic Harold Bloom: "We read because we cannot know enough people."
} 
Table 1 Lucy's three types or levels of linguistic relativity (Lucy 1997, p. 292)

\begin{tabular}{l|c}
\hline Type or level of linguistic relativity & Characterization \\
\hline Semiotic & $\begin{array}{c}\text { "How speaking any natural language at all may influence thinking"; does having a code } \\
\text { with a symbolic component transform thinking? }\end{array}$ \\
\hline Structural & $\begin{array}{c}\text { "How speaking one or more particular natural languages (e.g., Hopi versus English) may } \\
\text { influence thinking"; do quite different morphosyntactic configurations of meaning } \\
\text { affect thinking about reality? }\end{array}$ \\
\hline Discursive & $\begin{array}{c}\text { "Whether using language in a particular way (e.g., schooled) may influence thinking"; do } \\
\text { discursive practices affect thinking either by modulating structural influences } \\
\text { or by directly influencing the interpretation of the interactional context? }\end{array}$ \\
\hline
\end{tabular}

In spite of various objections and misconstruals, Neo-Whorfian explorations developed and extended Whorf's ideas toward the end of the century and ever since (see Brown \& Lenneberg 1954; Brown et al. 1958; Hymes 1966; Rosch 1977; Silverstein 1979; Hale 1986; Wierzbicka 1989; Schultz 1990; Hill \& Mannheim 1992; Lucy 1992, 1996; Gumperz \& Levinson 1996; Michael 2002; Gentner \& Goldin-Meadow 2003; Kockelman 2010; Webster 2014; among many others; Whorf 2012 includes an extended bibliography). The work has covered much ground; the case has been made both for and against a linguistic relativity hypothesis, often in strong terms, from multiple perspectives, in relation to a range of (usually nonsocial) ontological domains, including color, space, and time, and using a range of methodologies.

Over the past couple of decades, people have tried to define or characterize possible types or elements of linguistic relativity. This has been done not just as a step toward better understanding, but also as a way of singling out the lines of work that may be most worthwhile pursuing, for example because they are methodologically more tractable, conceptually more coherent, or empirically more promising.

As we can now see, the pie can be cut in many ways. Lucy (1997, p. 292), for example, suggests that there are "three types or levels" of linguistic relativity (Table 1; see also Lucy 1992, 1996).

Bloom \& Keil (2001, pp. 352-53) identify four loci at which distinctions can be made; there is partial overlap with Lucy's (1997) taxonomy (Table 2).

Wolff \& Holmes (2011, p. 254) distinguish seven "classes and subclasses of hypotheses on how language might affect thought." Two of these are briefly considered and dismissed from the scope of interest: first, the idea that language affects thought because thought $i$ language, and second, the idea that while thought and language are separate, language can determine and overwrite

Table 2 Bloom \& Keil's (2001, pp. 352-53) distinctions in linguistic relativity effects

\begin{tabular}{l|l}
\hline Locus of distinction & \multicolumn{1}{c}{ Contrast } \\
\hline Language versus languages & $\begin{array}{l}\text { Effects that are language-general (i.e., effects of having language versus not having it) } \\
\text { versus effects that are language-specific (i.e., from being a speaker of Language X versus } \\
\text { Language Y) }\end{array}$ \\
\hline Parts of language that matter & Syntax versus words \\
\hline Mygnitude of effect & Mild versus massive \\
\hline $\begin{array}{l}\text { Produce effects on our online perception of the world } \\
\text { Shape the categories we form } \\
\text { Enable us to perform logical inference and causal reasoning } \\
\text { Produce effects on how we structure our basic ontological commitments (about time, } \\
\text { space, matter) }\end{array}$ \\
\hline
\end{tabular}


Table 3 Wolff \& Holmes' (2011, p. 254) five ways that we see effects of language on thought

\begin{tabular}{l|l|l}
\hline & \multicolumn{1}{|c}{$\begin{array}{c}\text { Type or level of } \\
\text { linguistic relativity }\end{array}$} & \multicolumn{1}{c}{ Characterization } \\
\hline $\begin{array}{l}\text { Thinking before } \\
\text { language }\end{array}$ & \begin{tabular}{l} 
Thinking for speaking \\
\multirow{2}{*}{$\begin{array}{l}\text { Thinking with } \\
\text { language }\end{array}$}
\end{tabular} & $\begin{array}{c}\text { "Encoding for later expression"; i.e., how we think about an experience may be } \\
\text { guided by considerations for how we may have to code it linguistically later on }\end{array}$ \\
\cline { 2 - 3 } $\begin{array}{l}\text { Thinking after } \\
\text { language }\end{array}$ & Language as augmenter & "Linguistic representations extend/enable nonlinguistic representations" \\
\cline { 2 - 3 } & Language as spotlight & "Language makes certain properties highly salient in nonlinguistic thinking" \\
\hline
\end{tabular}

patterns of thought. Wolff \& Holmes are interested instead in five remaining ways by which we may see a language-thought relationship, each of which begins with the assumption that "thought and language differ structurally" (Table 3).

Other recent taxonomies include Reines \& Prinz's (2009, pp. 1027-28) four types of linguistic relativity (radical, trivial, habitual, and ontological) and Gentner \& Goldin-Meadow's (2003, pp. 9-10) three types of language-thought relation (language as lens, language as tool kit, and language as category maker). As these sources show, the project has now gone well beyond Whorf's specific observations and suggestions. Much of the extensive literature is reviewed in the articles cited above, as well as in book-length review treatments, most recently by Leavitt (2010) and Everett (2013); see also the wide-ranging bibliography in Whorf (2012). There we see many ways that language diversity correlates with patterns of cognitive diversity: Our visual perception and categorization of color distinctions can be affected by cross-language differences in color vocabularies (Roberson et al. 2005, Winawer et al. 2007, Roberson \& Hanley 2010); our implicit evaluations of the characteristics of inanimate objects such as bridges can be affected by whether the relevant word is grammatically feminine (as for "bridge" in German) or masculine (as in Spanish; Boroditsky et al. 2003); our reasoning about spatial relations can be affected by the frame of reference that is dominant in a language (cardinal directions in some languages versus left/right in others; Haviland 1993, Levinson 2003b, Majid et al. 2004, Haun et al. 2011). Further examples abound.

\section{NEW DIRECTIONS}

So we can no longer say, as Lucy (1997, p. 291) could nearly 20 years ago, that there is "relatively little empirical research" on linguistic relativity. But the research that has been done, penetrating as it is, has covered only a thin slice of the possible scope of this topic because Neo-Whorfian work has been fairly consistent in its narrow interpretation of the three key concepts. Reality has been taken to mean the realm of objective, nonsocial facts: "concepts of 'time,' 'space,' and 'matter'" (Whorf 2012, p. 178). Thought or mind has been taken to mean general, nonsocial cognition: forms of categorization, reasoning, and memory about reality as perceived. And language has mostly been taken to refer to structural and semantic features, synchronically framed, with a focus on the referential functions of words and other linguistic signs. Restricting the scope in this way has delivered valuable progress. But it is time to consider the larger space of things that could or should be regarded as instances of linguistic relativity.

Several important contributions to the linguistic anthropological literature have recognized the limitations of dominant work on linguistic relativity and have pointed to ways forward. Hymes (1966) proposed a "second type" of linguistic relativity, having to do with the effects of culture on the social functions of language. Silverstein $(1976,1979)$ built upon this idea and elaborated a 
view of linguistic relativity that follows from the fact that "people not only speak about, or refer to, the world 'out there'-outside of language-they also presuppose (or reflect) and create (or fashion) a good deal of social reality by the very activity of using language" (Silverstein 1976, p. 194). He identified language ideology - in particular the native view that language is mostly for referring to things - as a force that "affects the strategy of language use" (Silverstein 1979, p. 194). Friedrich $(1979,1986)$, Sherzer (1987), and Webster (2014) have called for due attention to be paid to relativity in the poetic functions of language (cf. Leavitt 2011, p. 201; see below). And Michael (2002) presents an approach to linguistic relativity that is concerned not with the impact of referential semantics on individual thought, but with the inherently social question of "how concrete discursive practice impacts processes of distributed cognition" (Michael 2002, p. 114; cf. also Everett 2005, 2012; Zinken \& Ogiermann 2013).

To build upon efforts such as these, and to identify candidate lines of work for sustained attention, researchers must chart a full possibility space by reconsidering the core elements of the linguistic relativity idea: language, mind, and reality. In the following sections we briefly consider only two dimensions along which a possibility space could be mapped: the multiple functions of language beyond reference, and the type of reality that exists solely by virtue of our beliefs and commitments, namely, social reality.

\section{Language and Its Functions}

Most Neo-Whorfian work has taken language to be primarily a referential device. Li \& Gleitman (2002, p. 266), for example, explicitly identify language as a "means for making reference to the objects, relations, properties, and events that populate our everyday world." But the referential function of language is just one among several (Austin 1962; Silverstein 1976, 1979, 1981, 2014; Zinken 2008; Kockelman 2010). Jakobson (1960) defined six basic types of functions that a piece of linguistic behavior can have: emotive, poetic, conative, referential, phatic, and metalingual. These functions are nonexclusive. Any swatch of language can usually be seen to perform several if not all of these functions at once. This is not just a conceptually useful scheme; it is theoretically well grounded in the core elements of a communicative act involving two people and a shared code: sender, message, addressee, context, channel, and code (cf. Shannon 1948). Thus, whereas the referential function orients to the context, picking out or construing objects and events for mutual attention, the phatic function, for example, orients to the channel, opening up or maintaining a connection between interlocutors.

So we could, for example, frame the matter of linguistic relativity in terms of language's phatic function, and we would surely see significant diversity in this functional domain as an outcome of the language being used. Consider a form of linguistic relativity implied by differences in the modality of a language: audible-plus-visible in the case of spoken language versus visible-only in the case of sign language. Opening up and maintaining a connection between interlocutors is a very different matter in a spoken language than it is for deaf people using a sign language (Baker 1977, Wilbur \& Petitto 1981, Lieberman 2014). The differences have implications both for cognition and for action:

Deaf children interacting through the visual mode must take into account their interlocutor's perceptual state in order to carry out a successful interaction. A deaf child must understand that it is not enough to be able to see his intended addressee but that the addressee also must be visually attending to the child as well. Thus, before any conversational turns can take place, a child must first evaluate the locus of attention of his addressee and then obtain the addressee's attention if it is directed elsewhere. Only 
when visual attention is established can a successful interaction take place. This ability to take into account another person's locus of attention arguably requires a level of visual perspective-taking skill that typically does not develop before the age of 24 months. (Lieberman 2014, p. 2)

As Lieberman explains, in adult signed discourse, "attention is obtained using a set of conventional behaviors, including tapping the addressee, waving a hand in the addressee's line of vision, pounding a surface, or even stomping one's foot" (Lieberman 2014, p. 2). When the channel of communication becomes a locus of contention-as happens for example in confrontational talk between intimates-again modality-specific effects are heightened. In a quarrel in sign language, a person may force the channel to stay open by physically turning someone's face toward them (and hence their gaze) if they have looked away; or they may force the channel shut by closing their eyes or even by holding an interlocutor's arm or wrist to prevent them from signing. ${ }^{4}$ Quite different manipulations of the channel would be implied in the case of spoken language.

These examples suggest the possibility of a form of linguistic relativity grounded in the phatic function of language and manifest in the domain of social attention and action rather than (solely) in perception, conceptual structure, or reasoning. Forms of linguistic relativity such as these are not included in the taxonomies given above (Tables 1-3), precisely because those taxonomies focus on language's referential function and on the relatively private and nonsocial psychological domains of conceptual structure and reasoning.

What is wrong with focusing our attentions solely on the referential function of language? The answer is that there is no objective basis for regarding the referential function-or any other of these functions-as the core function of language (independent from possible claims of the uniqueness of this function in language). Research on linguistic relativity must therefore in principle give equal attention to these other functions of language (this point has of course been made before: see Friedrich 1986 for an extended exploration of linguistic relativity in relation to the poetic function of language; see also Sherzer 1987; Dingemanse 2011, 2014; Webster 2014).

Why is the referential function so widely treated as the privileged or main function of language? One reason is that currently dominant work on linguistic relativity is carried out within research frameworks such as psycholinguistics that have been heavily focused on reference. This focus is, in turn, a function of linguistic ideology grounded ultimately in our natural cognitive habits of linguistic awareness (Silverstein 1981): It is easier to single out and focus our attention on the referential function than on other functions, leading us naturally to gravitate to it in any kind of metasemiotic practice, including in our research (Silverstein 2014). Although the restriction to reference may be explained in terms of these inherent disciplinary, ideological, or cognitive limitations, it may also simply have been a shrewd methodological choice, giving the work the focus needed to achieve its ample successes. Whatever the case, such self-imposed limitations should not be allowed to stay in place for too long.

Reference-oriented approaches to linguistic relativity will benefit from more serious engagement with approaches to language that have tended to view it as a tool with a broad functional scope (Enfield et al. 2014). Kockelman (2010), for example, exemplifies an approach that looks for multiple structural and functional domains of language in which a particular cultural and cognitive perspective can be repeatedly manifest. On this approach, linguistic categories in a given

\footnotetext{
${ }^{4}$ Thanks go to Trevor Johnston and Adam Schembri for helpful information about these aspects of sign language usage.
} 
ethnolinguistic ecology are analyzed not just with respect to words or grammatical constructions, but in light of the full gamut of "morphosyntactic forms, semantic features, pragmatic functions, and discourse frequencies" that may be both signs of and causes of linguistic relativity effects (Kockelman 2010). A linguistic-anthropological program is particularly promising not only because it seeks to draw on multiple types of phenomena in pursuing a proper understanding of linguistic relativity — beyond the referential function of language — but also because it ultimately looks to understand the relationships between these types and with their social, cultural, and cognitive contexts.

\section{Language and Social Reality}

Lucy (1997, p. 291) defined linguistic relativity with this question: "Does the particular language we speak influence the way we think about reality?" Some have even said that reality itself can be different from the perspective of different languages. As Sapir put it, "The 'real world' is to a large extent unconsciously built up on the language habits of the group" (Sapir 1949, p. 162). The idea that a language can determine a state of reality makes little sense if the word reality is understood in the usual Neo-Whorfian sense of brute reality. But how might differences among languages affect social reality? Searle (1969, 2010), following Austin (1962), has long argued not only that social or institutional reality can be created using language - as when the words used in wedding vows create new rights and duties-but that all social-institutional reality, from monetary values to property rights to corporate identity, is built from language and cannot exist without it. What is of interest here is that whenever language is used to create social reality in these ways, it is never just language but always $a$ language. And again, because we know that the conceptual distinctions made available by different languages can differ radically, then linguistic diversity implies diversity in the kinds of reality that language can create.

Obvious examples concern the explicit performatives that are used for formally bestowing new statuses, such as vows, initiations, and christenings. The relevant words and concepts for such rituals in different languages and communities will be as diverse in content as the ethnographic contexts of their use. But consider the rights and duties that words can bestow in a less formal sense, namely the social accountability that all speech acts presuppose and/or create (Heritage 1984, Sacks 1992). If I assert that something is true, then I become publicly accountable for having done so. If what I asserted turns out to be untrue, then I can be said to have lied or to have been mistaken. Or if what I asserted turns out to be amazing, then I can be praised and celebrated. Such accountability—both negative and positive-shows that the language-specific meanings of linguistic forms can be directly implicated in the construction of a form of social reality that defines how others may respond to us and that thus defines our very selves (Linton 1936, Goffman 1959). If we acknowledge that language by its nature is the tool through which our social selves are created, through the creation and distribution of rights and duties, then different languages will differently determine the kinds of selves we can have.

As discussed above, Whorf's example of the "empty" gasoline drums is usually understood as being about reasoning, implying that the person involved used the word empty in some sort of internal dialogue, which led them to make a certain decision: "Empty" means no gasoline, which implies that it is not dangerous. Another way to frame it, though, is that the effect has to do with the linguistic presupposition and creation of social accountability. The situation Whorf was writing about was precisely this: an insurance case in which culpability was being assessed. The status of the word empty, in this account, is not just as a guide for private thought, but also as a potential basis for public defense if someone were held accountable for his/her behavior. Now because the person's language-English in this instance-has the word empty, with all of 
its semantic/pragmatic properties, the person has certain forms of accountability available to him and, in turn, is subject to those forms of accountability.

We see in social interaction that people use fine distinctions in word meaning to negotiate rights and duties associated with the social situations they find themselves in. Sidnell \& Barnes (2013) describe a case in which two children dispute whether one of them had "tapped" an object or "poked" it, with obvious implications for culpability depending on whose version is accepted. Thus, any such semantic distinction implies the possibility of accountability, and that possibility is always present in social interaction (Garfinkel 1967). It suggests the following prediction: If a language makes fine distinctions in meaning in some domain, people who speak that language will be subject to a different normative background for interpretation and accountability than they would be in the context of a language that does not make the same fine distinctions.

Consider any of the countless studies demonstrating that a semantic domain is finely differentiated in the vocabulary of one language but not in another. What, for example, is the significance of the fact that the Maniq language of Southern Thailand features a special semantic elaboration of reference to odors that is not found in English (Wnuk \& Majid 2014)? We may observe that this elaboration correlates with (implying is caused by) a special cultural concern with odors (Wnuk \& Majid 2014; see also Majid \& Burenhult 2014). But if we are going to explain why words exist, what we need to explain is not why people think those thoughts but why they use those words. We need a motivation for people not just to make the distinction, but also to make the distinction public (Enfield 2015). Invoking social accountability for behavior-including linguistic behavior-is an important function of words and, thus, an important reason why people will use the words they use in social life. So we can predict that because a Maniq speaker can make differentiations of reference to smell in her language, she may be held accountable by other speakers for having incorrectly made, or for not having made, available linguistic distinctions in referring to a certain smell that may have been perceived. Without such distinctions in one's language, it is surely less likely that such accountability will be presupposed or anticipated.

The semantic distinctions made in your language conspire to create a "web of inferences" (Levinson 1983, p. 321) — that is, you can use only the words that local convention provides, and you must also accept and work within the likely or inevitable patterns of interpretation or inference that others in your community will apply. For instance, as Grice (1989) insisted, whatever you say may be used as evidence of what you are choosing not to say. The crucial point here is that such inferences are made relative to an available linguistic system, and thus the constraints you face in inviting or avoiding possible inferences when formulating linguistic actions in context are linguistically relative constraints.

Because language itself is a kind of social reality, we can consider the effects of language even on language itself as a candidate domain for linguistic relativity effects. Take the case of typological dependencies among subsystems in languages. If verbs come after objects in a language ("She rice ate" rather than "She ate rice"), then it will be more likely in that language that adpositions will come after nouns ("the table on" rather than "on the table"; Greenberg 1966, Croft 2003). The reason for this correlation is that the two types of relation-verb-object and nounadposition-are not independent, often because they historically derive from the same source, through social processes that are mediated by psychological tendencies to preserve harmony in mental representation (Enfield 2014, pp. 17-19).

It therefore seems possible that typological dependencies between subsystems of language present a candidate instance of linguistic relativity. They show that the way reality is created (i.e., the diachronic creation of social-cultural reality in the form of linguistic convention), via ontogenetic and microgenetic processes of thought and behavior, will differ depending on the initial state of the linguistic system. We know that inference drives grammaticalization, and we 
know that the inferences people make are the ones made possible or likely by the state of the system (Hopper \& Traugott 1993). If the state of language spoken determines the operative patterns of markedness and their expressive and interpretive effects, then possible changes or next states in a language - mediated by the thoughts and actions of its users (Enfield 2014, p. 19)—are defined relative to the current state of the language and by the norms of its established usage patterns.

In a final example of linguistically relative effects on social reality, consider work that focuses on language in social interaction as a tool for constructing social actions (Sacks 1992, Schegloff 2006, Sidnell \& Stivers 2012, Enfield \& Sidnell 2014, Jefferson 2015). Research in this area is becoming increasingly comparative (see Sidnell 2007, 2009; Stivers et al. 2009; Zinken \& Ogiermann 2011; Dingemanse \& Enfield 2014; Dingemanse \& Floyd 2014), thus opening up a new horizon for linguistic relativity effects. As Couper-Kuhlen \& Selting (2001, p. 8) hint, "the way interaction itself is conducted may be influenced by (typologically) different language practices."

Sidnell \& Enfield (2012) make the case with a comparative study of speech act formation in Creole, Finnish, and Lao by considering how these languages use different grammatical resources to construct the same rather specific pragmatic action, that of "agreeing with what someone just said while conveying that one has greater authority to say it" (Sidnell \& Enfield 2012, p. 320). When Creole speakers perform this action, they use a linguistic practice that "treats the prior turn as uncertain"; the Finnish practice effects the same action but in addition "foregrounds different perspectives"; and the Lao practice "introduces a sense of finality" in addition to effecting the basic action. The linguistic relativity effect being observed here is not about the things that different languages can make you think. It is about the different rights and duties that speech acts in languages can give you. The example reveals that language-specific side-effects on normative obligations in a next conversational move arise because of the unavoidable introduction of collateral effects when communicative tools have multiple functional features:

\footnotetext{
Because such social action is done with the tools that our languages provide and because these tools are structurally overdetermined through their rich meanings and multiple functions, the conventionalized selection of such tools will have language-specific collateral effects on the final nature of the action. On this view, the language you speak makes a difference in the social actions you can perform. The language-specific vehicle or means for an action-even where that action is a general goal or end that we expect people will want to pursue in any cultural context-will shape the action as a function of the structures it introduces. ... Differences in language structure lead to linguistically relative collateral effects, which lead in turn to differences in our very possibilities for social agency. (Sidnell \& Enfield 2012, pp. 320-21)
}

Only when we frame language in terms of agency will we properly understand the ways in which it is used to create social reality. Recent advances in the conception of language and agency (Ahearn 2001, Duranti 2004, Kockelman 2007, Enfield \& Kockelman 2016) are helping to place language function within the dynamic distribution of mind, where mind is understood as active, distributed, and social-relational in nature (Enfield 2013). With language as a semiotic system of means to ends (Zipf 1949), its users acquire, claim, and develop rights and duties in relation to the defining elements of linguistic agency: flexibility and accountability. Thought of in this light, linguistic relativity is readily observed and understood in new ways. If our patterns of linguistic residence and representation are defined in terms of semiotic flexibility and accountability (Kockelman 2013) both social-relational notions at their core-then the scope of linguistic relativity broadens: Our attention shifts naturally from reference to agency. 


\section{CONCLUSION}

Linguistic diversity is causally related to cultural and cognitive diversity in numerous ways. Some effects of language on thought are now widely acknowledged to be real. But their possible interactions with the true diversity of human languages remain understudied. We do not know if effects such as verbal overshadowing are the same for all members of our language-using species, partly because we are still mapping the real extent of semantic and grammatical diversity. Imagine that linguists discovered a language with a vocabulary for faces so perfect that you could recognize a person from the verbal description alone. An attacker's face would no longer "defy complete linguistic description," with the result that words in that language would not overshadow people's memory for faces, and we could expect lower rates of wrongful conviction in that community based on witness misidentification. Linguistic fieldwork may yet uncover such a language, with a fine vocabulary for faces, but in the meantime we know that English is not it (Schooler \& Engstler-Schooler 1990).

Not all the known effects of language on thought are as consequential as the witness misidentifications that can destroy people's lives. And not all linguistic effects are as innocuous as many Neo-Whorfian findings seem to be: a subtle perturbation that color vocabulary can create in one eye but not the other (Gilbert et al. 2006), or a subconscious sexual stereotyping of inanimate objects such as keys or bridges in association with the grammatical gender of words (Boroditsky et al. 2003). Those who admit only a weak version of linguistic relativity sometimes add that the weak version is trivial or uninteresting. The problem with doing so is that we have no independent measure of what we should find interesting. An effect of language on thought is an effect of language on thought. If it means a speaker of one language is more likely to come home from the hardware store with the wrong shade of paint, then that might sound harmless, but not if it leads to a domestic argument. Nor is it harmless if a worker is more likely to cause a factory fire-or to misjudge his own potential culpability—or if a witness is more likely to put a man in prison for a crime he didn't commit. So we cannot and must not dismiss as trivial the possibility that the effects of language on thought and social reality can influence behavior and thereby affect our lives. Whether they do remains an empirical question.

Neo-Whorfian work has made real advances, but it has covered too little ground, given its narrow, nonsocial definitions of the key concepts. More imagination is needed. The mind, including the parts that are built through language, is a purpose-made tool kit for cognitive and social action, just as a body is a tool kit for physical action. And because languages are so differently structured, each one is like the body plan of a different species, affording its users different ranges of possibilities.

A language, then, does not imprison you; it equips you. A language is not a straitjacket; it is an action suit. Whorfian approaches to linguistic relativity have been concerned with the idea that people with different languages are "not equivalent as observers" (Whorf 2012, p. 283). We must now explore the idea that people who have different languages are not equivalent as agents.

\section{SUMMARY POINTS}

1. Neo-Whorfian approaches to linguistic relativity have thrived over the past two decades, thanks to an inspired generation of researchers, mostly with an orientation to psychology and its methods. Empirical work has yielded findings and insights that allow us to better test, analyze, and understand linguistic relativity phenomena. 
2. The conceptual limits of Whorfianism have become virtually naturalized. The specific way that Whorf happened to characterize the three key elements of linguistic relativitylanguage as reference, thought as perception and reasoning, and reality as the physical world-has now been so widely adopted that other understandings of these elements now remain largely out of view in research on linguistic relativity.

3. The key elements of linguistic relativity—language, mind, and reality—can each be understood in diverse ways. There is more to language than reference, more to mind than perception and reasoning, and more to reality than the physical world.

\section{FUTURE DIRECTIONS}

1. There is much room for new research on relativity effects relating to functions of language other than reference; these include the emotive, poetic, conative, phatic, and metalingual functions of language. Although some work is already exploring these functional domains, in some ways even the most basic work remains to be done.

2. Aspects of mind beyond perception and its link to reasoning will be fertile ground for further linguistic relativity research. Promising directions for research on the effects of language differences on mind include the emotions, personhood, and the distribution of agency.

3. Whorfian claims are particularly striking when they imply that physical reality can be different for speakers of different languages. There is another form of reality-social or institutional reality-that is no less real in human affairs. Because social reality is arguably itself a product of language, it is particularly amenable to investigation as a locus of linguistic relativity.

4. Acknowledgment of the full breadth of understandings of the core concepts-language, mind, and reality — should lead to the development of broader, richer, more nuanced definitions of linguistic relativity. The central claim of linguistic relativity could be defined as follows: If two people speak two different languages, these people will have significantly different perspectives; this means that they may feel, think, and act differently or may be treated differently from each other because of the language they speak. It may mean not only that they could come to have different understandings of reality, but also that they may be able to create different understandings of reality in other people. Further work must explore the possibility that speakers of different languages can be different kinds of agents and patients and, thus, different kinds of people.

\section{DISCLOSURE STATEMENT}

The author is not aware of any affiliations, memberships, funding, or financial holdings that might be perceived as affecting the objectivity of this review.

\section{ACKNOWLEDGMENTS}

I am grateful to Mark Dingemanse, Paul Kockelman, Jack Sidnell, and Michael Silverstein for helpful input and guidance. 


\section{LITERATURE CITED}

Ahearn L. 2001. Language and agency. Annu. Rev. Antbropol. 30:109-37

Austin JL. 1962. How to Do Things with Words. Cambridge, MA: Harvard Univ. Press

Baker C. 1977. Regulators and turn-taking in American Sign Language discourse. In On the Other Hand: New Perspectives on American Sign Language, ed. L Friedman, pp. 215-36. New York: Academic

Bloom P, Keil FC. 2001. Thinking through language. Mind Lang. 16:351-67

Boas F. 1966 (1911). Introduction. In Handbook of American Indian Languages, ed. F Boas, pp. 1-79. Lincoln: Univ. Neb. Press

Boghossian P. 2006. Fear of Knowledge. London: Clarendon

Boroditsky L, Schmidt L, Phillips W. 2003. Sex, syntax, and semantics. In Language in Mind: Advances in the Study of Language and Cognition, ed. G Dedre, S Goldin-Meadow, pp. 61-80. Cambridge, MA: MIT Press

Bowerman M, Levinson SC, eds. 2001. Language Acquisition and Conceptual Development. Cambridge, UK: Cambridge Univ. Press

Brown R, Lenneberg EH. 1954. A study in language and cognition. F. Abnorm. Soc. Psychol. 49:454-62

Brown RW, Copi IM, Dulaney DE, Frankena WK, Henle P, Stevenson CL. 1958. Language, Thought, and Culture. Ann Arbor: Univ. Mich. Press

Cohen H, Lefebvre C, eds. 2005. Handbook of Categorization in Cognitive Science. Oxford, UK: Elsevier

Couper-Kuhlen E, Selting M. 2001. Introducing interactional linguistics. In Studies in Interactional Linguistics, ed. M Selting, E Couper-Kuhlen, pp. 1-22. Amsterdam: Benjamins

Croft W. 2003. Typology and Universals. Cambridge, UK: Cambridge Univ. Press. 2nd ed.

Dingemanse M. 2011. Ezra Pound among the Mawu: ideophones and iconicity in Siwu. In Semblance and Signification, ed. P Michelucci, O Fischer, C Ljungberg, pp. 39-54. Iconicity Lang. Lit. 10. Amsterdam: John Benjamins

Dingemanse M. 2014. Making new ideophones in Siwu: creative depiction in conversation. Pragmat. Soc. 5(3):384-405

Dingemanse M, Enfield NJ. 2014. Other-initiated repair across languages: towards a typology of conversational structures. Open Linguist. 1:96-118

Dingemanse M, Floyd S. 2014. Conversation across cultures. See Enfield et al. 2014, pp. 447-80

Duranti A. 2004. Agency in language. In A Companion to Linguistic Anthropology, ed. A Duranti, pp. 451-73. Malden, MA: Blackwell

Enfield NJ. 2013. Relationship Thinking: Enchrony, Agency, and Human Sociality. New York: Oxford Univ. Press

Enfield NJ. 2014. Natural Causes of Language: Frames, Biases, and Cultural Transmission. Berlin: Lang. Sci.

Enfield NJ. 2015. The Utility of Meaning: What Words Mean and Why. Oxford, UK: Oxford Univ. Press

Enfield NJ, Kockelman P, Sidnell J, eds. 2014. The Cambridge Handbook of Linguistic Antbropology. Cambridge, UK: Cambridge Univ. Press

Enfield NJ, Kockelman P. 2016. Distributed Agency. New York: Oxford Univ. Press. In press

Enfield NJ, Sidnell J. 2014. Language presupposes an enchronic infrastructure for social interaction. In The Social Origins of Language, ed. D Dor, C Knight, J Lewis, pp. 92-104. Oxford, UK: Oxford Univ. Press

Evans ND. 2010a. Dying Words: Endangered Languages and What They Have to Tell Us. Chichester, UK: Wiley

Evans ND. 2010b. Semantic typology. In The Oxford Handbook of Linguistic Typology, ed. JJ Song, pp. 504-33. Oxford, UK: Oxford Univ. Press

Everett DL. 2005. Cultural constraints on grammar and cognition in Pirahã: another look at the design features of human language. Curr. Antbropol. 46(4):621-46

Everett DL. 2012. Language: The Cultural Tool. London: Profile

Everett C. 2013. Linguistic Relativity: Evidence Across Languages and Cognitive Domains. Berlin/Boston: De Gruyter Mouton

Friedrich P. 1979. Language, context, and the imagination. Stanford, CA: Stanford Univ. Press

Friedrich P. 1986. The Language Parallax. Austin: Univ. Tex. Press

Garfinkel H. 1967. Studies in Ethnomethodology. Englewood Cliffs, NJ: Prentice-Hall

Gentner D, Goldin-Meadow S. 2003. Language in Mind: Advances in the Study of Language and Thought. Cambridge, MA: MIT Press

Gibson JJ. 1979. The Ecological Approach to Visual Perception. Boston: Houghton Mifflin 
Gigerenzer G. 2007. Gut Feelings: Short Cuts to Better Decision Making. London: Penguin

Gigerenzer G, Hertwig R, Pachur T, eds. 2011. Heuristics: The Foundations of Adaptive Behavior. New York: Oxford Univ. Press

Gilbert AL, Regier T, Kay P, Ivry RB. 2006. Whorf hypothesis is supported in the right visual field but not the left. PNAS 103(2):489-94

Goddard C, Wierzbicka A. 2014. Words and Meanings: Lexical Semantics Across Domains, Languages, and Cultures. Oxford, UK: Oxford Univ. Press

Goffman E. 1959. The Presentation of Self in Everyday Life. New York: Anchor Books

Greenberg JH. 1966. Some universals of grammar with particular reference to the order of meaningful elements. In Universals of Language, ed. JH Greenberg, pp. 73-113. Cambridge, MA: MIT Press. 2nd ed.

Grice HP. 1989. Studies in the Way of Words. Cambridge, MA: Harvard Univ. Press

Grimes J. 1996. On the failure to detect changes in scenes across saccades. In Vancouver Studies in Cognitive Science: Vol. 2: Perception, ed. K Akins, pp. 89-110. New York: Oxford Univ. Press

Gumperz JJ, Levinson SC, eds. 1996. Rethinking Linguistic Relativity. Cambridge, UK: Cambridge Univ. Press

Hale KL. 1986. Notes on world view and semantic categories: some Warlpiri examples. In Features and Projections, ed. P Muysken, H van Riemsdijk, pp. 233-54. Dordrecht, The Neth.: Foris

Haun D, Rapold C, Janzen G, Levinson S. 2011. Plasticity of human spatial cognition: spatial language and cognition covary across cultures. Cognition 119:70-80

Haviland J. 1993. Anchoring, iconicity, and orientation in Guugu Yimithirr pointing gestures. 7. Linguist. Anthropol. 3(1):3-45

Herder JG. 1992. Selected Early Works, 1764-1767. Burlington, VT: Edward Smith

Heritage J. 1984. Garfinkel and Ethnomethodology. Cambridge, UK: Polity

Hill JH, Mannheim B. 1992. Language and world view. Annu. Rev. Anthropol. 21:381-406

Hopper PJ, Traugott EC. 1993. Grammaticalization. Cambridge, UK: Cambridge Univ. Press

von Humboldt W. 1988 (1836). On Language: The Diversity of Human Language-Structure and Its Influence on the Mental Development of Mankind. Cambridge, UK: Cambridge Univ. Press

Hymes D. 1966. Two types of linguistic relativity (with examples from Amerindian ethnography). In Sociolinguistics, Proc. UCLA Socioling. Conf., 1964, ed. W Bright, pp. 114-67. The Hague: Mouton

Ingold T. 2000. The Perception of the Environment Essays on Livelihood, Dwelling and Skill. London/New York: Routledge

Jakobson R. 1960. Concluding statement: linguistics and poetics. In Style in Language, ed. TA Sebeok, pp. 350-77. Cambridge, MA: MIT Press

Jefferson G. 2015. Talking About Troubles in Conversation. New York: Oxford Univ. Press

Kahneman D. 2011. Thinking, Fast and Slow. New York: Penguin

Kerr AD. 1972. Lao-English Dictionary. Washington, DC: Cathol. Univ. Am. Press

Kockelman P. 2007. Agency: the relation between meaning, power, and knowledge. Curr. Anthropol. 48(3):375401

Kockelman P. 2010. Language, Culture, and Mind: Natural Constructions and Social Kinds. Cambridge, UK: Cambridge Univ. Press

Kockelman P. 2013. Agent, Person, Subject, Self: A Theory of Ontology, Interaction, and Infrastructure. Oxford, UK: Oxford Univ. Press

Leavitt J. 2010. Linguistic Relativities: Language Diversity and Modern Thought. Cambridge, UK: Cambridge Univ. Press

Lee P. 1996. The Whorf Theory Complex: A Critical Reconstruction. Amsterdam/New York: John Benjamins

Levinson SC. 1983. Pragmatics. Cambridge, UK: Cambridge Univ. Press

Levinson SC. 2003a. Language and mind: Let's get the issues straight. In Language and Mind: Advances in the Study of Language and Thought, ed. D Gentner, S Goldin-Meadow, pp. 25-46. Cambridge, MA: MIT Press

Levinson SC. 2003b. Space in Language and Cognition: Explorations in Cognitive Diversity. Cambridge, UK: Cambridge Univ. Press

Levinson SC. 2012. Foreword. In Whorf 2012, pp. vii-xxiii 
Levinson SC, Majid A. 2014. Differential ineffability and the senses. Mind Lang. 29:407-27

Li P, Gleitman L. 2002. Turning the tables: language and spatial reasoning. Cognition 83:265-94

Lieberman AM. 2014. Attention-getting skills of deaf children using American Sign Language in a preschool classroom. Appl. Psycholing. 2014:1-19

Linton R. 1936. The Study of Man: An Introduction. New York: Appleton-Century-Crofts

Loftus EF, Palmer JC. 1974. Reconstruction of automobile destruction: an example of the interaction between language and memory. F. Verbal Learn. Verbal Behav. 13(5):585-89

Lucy J. 1992. Language Diversity and Thought: A Reformulation of the Linguistic Relativity Hypothesis. Cambridge, UK: Cambridge Univ. Press

Lucy J. 1996. The scope of linguistic relativity. See Gumperz \& Levinson 1996, pp. 37-69

Lucy J. 1997. Linguistic relativity. Anпи. Rev. Anthropol. 26:291-312

Lupyan G. 2008. From chair to 'chair': a representational shift account of object labeling effects on memory. 7. Exp. Psychol. Gen. 137:348-69

Majid A, Bowerman M, Kita S, et al. 2004. Can language restructure cognition? The case for space. Trends Cogn. Sci. 8:108-14

Majid A, Burenhult N. 2014. Odors are expressible in language, as long as you speak the right language. Cognition 130.2:266-70

Malt BC, Wolff P, eds. 2010. Words and the Mind: How Words Capture Human Experience. New York: Oxford Univ. Press

Michael L. 2002. Reformulating the Sapir-Whorf hypothesis: discourse, interaction, and distributed cognition. Presented at Symp. About Lang. Soc. Austin (SALSA) X: 2002, ed. IMey, G Pizer, S His-Yao, S Szmania, Tex. Linguist. Forum, Vol. 45. Univ. Tex., Austin. http://studentorgs.utexas.edu/salsa/proceedings/2002/ papers/michael.pdf

McWhorter JH. 2014. The Language Hoax: Why the World Looks the Same in Any Language. New York: Oxford Univ. Press

Reines MF, Prinz J. 2009. Reviving Whorf: the return of linguistic relativity. Philos. Compass 4.6:1022-32

Riemer N. 2010. Introducing Semantics. Cambridge, UK: Cambridge Univ. Press

Roberson D, Davidoff J, Davies I, Shapiro L. 2005. Colour categories in Himba: evidence for the cultural relativity hypothesis. Cogn. Psychol. 50:378-411

Roberson D, Hanley R. 2010. Relatively speaking: an account of the relationship between language and thought in the color domain. See Malt \& Wolff 2010, pp. 183-98

Rosch E. 1977. Linguistic relativity. In Thinking: Readings in Cognitive Science, pp. 501-22. Cambridge, UK: Cambridge Univ. Press

Ryle G. 1949. The Concept of Mind. London: Hutchinson

Sacks H. 1992. Lectures on Conversation. London: Blackwell

Sapir E. 1949. Selected Writings. Berkeley: Univ. Calif. Press

Schegloff EA. 2006. Interaction: the infrastructure for social institutions, the natural ecological niche for language, and the arena in which culture is enacted. In Roots of Human Sociality: Culture, Cognition, and Interaction, ed. NJ Enfield, SC Levinson, pp. 70-96. Oxford, UK: Berg

Schooler JW, Engstler-Schooler TY. 1990. Verbal overshadowing of visual memories: Some things are better left unsaid. Cogn. Psychol. 22(1):36-71

Schultz E. 1990. Dialogue at the Margins: Whorf, Bakbtin, and Linguistic Relativity. Madison: Univ. Wis. Press Searle JR. 1969. Speech Acts: An Essay in the Philosophy of Language. Cambridge, UK: Cambridge Univ. Press Searle JR. 2010. Making the Social World: The Structure of Human Civilization. Oxford, UK: Oxford Univ. Press Shannon CE. 1948. A mathematical theory of communication. Bell Syst. Tech. 7. 27:379-423, 623-56

Sherzer J. 1987. A discourse-centered approach to language and culture. Am. Anthropol. 89:295-309

Sidnell J. 2007. Comparative studies in conversation analysis. Annu. Rev. Anthropol. 36:229-44

Sidnell J, ed. 2009. Conversation Analysis: Comparative Perspectives. Cambridge, UK: Cambridge Univ. Press

Sidnell J, Barnes R. 2013. Alternative, subsequent descriptions. In Conversational Repair and Human Understanding, ed. M Hayashi, G Raymond, J Sidnell, pp. 322-42. Cambridge, UK: Cambridge Univ. Press

Sidnell J, Enfield NJ. 2012. Language diversity and social action. Curr. Anthropol. 53(3):302-33

Sidnell J, Stivers T, eds. 2012. The Handbook of Conversation Analysis. Oxford, UK: Wiley-Blackwell 
Silverstein M. 1976. Shifters, linguistic categories, and cultural description. In Meaning in Antbropology, ed. K Basso, H Selby, pp. 11-55. Albuquerque: Univ. N. M. Press

Silverstein M. 1979. Language structure and linguistic ideology. In The Elements: A Parasession on Linguistic Units and Levels, ed. P Clyne, W Hanks, C Hofbauer, pp. 193-247. Chicago: Chicago Linguist. Soc.

Silverstein M. 1981. The limits of awareness. Socioling. Work. Pap., No. 84

Silverstein M. 2014. Denotation and the pragmatics of language. See Enfield et al. 2014, pp. 128-57

Simon HA. 1956. Rational choice and the structure of the environment. Psychol. Rev. 63(2):129-38

Simon HA. 1983. Reason in Human Affairs. Stanford, CA: Stanford Univ. Press

Simons DJ, Levin DT. 1997. Change blindness. Trends Cogn. Sci. 1(7):261-67

Stivers T, Enfield NJ, Brown P, Englert C, Hayashi M, et al. 2009. Universals and cultural variation in turn-taking in conversation. PNAS 106(26):10587-92

Taylor JR. 2004. Linguistic Categorization: Prototypes in Linguistic Theory. Oxford, UK: Clarendon. 3rd ed.

Webster AK. 2014. In favor of sound: linguistic relativity and Navajo poetry. Presented at Symp. About Lang. Soc. Austin (SALSA) XXII: 2014, ed. M Siewert, M Ingram, B Anderson, Tex. Linguist. Forum, Vol. 57. Univ. Tex., Austin. http://studentorgs.utexas.edu/salsa/proceedings/2014/Webster.pdf

Whorf BL. 2012. Language, Thought, and Reality. Cambridge, MA: MIT Press

Wierzbicka A. 1989. Baudouin De Courtenay and the theory of linguistic relativity. In fan Niecislaw Baudouin De Courtenay a Lingwistyka Swiatowa, pp. 51-57. Wroclaw: Ossolineum

Wilbur RB, Petitto LA. 1981. How to know a conversation when you see one: discourse structure in American Sign Language conversations. 7. Natl. Stud. Speech-Lang.-Hearing Assoc. 9:66-81

Winawer J, Witthoft N, Frank M, Wu L, Wade AR, Boroditsky L. 2007. Russian blues reveal effects of language on color discrimination. PNAS 104:7780-85

Wnuk E, Majid A. 2014. Revisiting the limits of language: the odor lexicon of Maniq. Cognition 131(1):125-38

Wolff P, Holmes KJ. 2011. Linguistic relativity. Wiley Interdiscip. Rev. Cogn. Sci. 2(3):253-65

Zinken J. 2008. The metaphor of "linguistic relativity." Hist. Philos. Psychol. 10(2):1-10

Zinken J, Ogiermann E. 2011. How to propose an action as an objective necessity: the case of Polish trzeba $x$ ("one needs to $x$ "). Res. Lang. Soc. Interact. 44(3):263-87

Zinken J, Ogiermann E. 2013. Responsibility and action: invariants and diversity in requests for objects in British English and Polish interaction. Res. Lang. Soc. Interact. 46(3):256-76

Zipf GK. 1949. Human Behaviour and the Principle of Least Effort. Cambridge, MA: Addison-Wesley 
Annual Review of Anthropology

Volume 44, 2015

\section{Contents}

\section{Perspective}

Some Things I Hope You Will Find Useful Even if Statistics

Isn't Your Thing

George L. Cowgill

Archaeology

Pleistocene Overkill and North American Mammalian Extinctions

David F. Meltzer

The Archaeology of Ritual

Edward Swenson

Recent Developments in High-Density Survey and Measurement

(HDSM) for Archaeology: Implications for Practice and Theory

Rachel Opitz and W. Fred Limp

Biological Anthropology

The Evolution of Difficult Childbirth and Helpless Hominin Infants

Holly Dunsworth and Leab Eccleston

Health of Indigenous Peoples

Claudia R. Valeggia and 7. Fosh Snodgrass

Energy Expenditure in Humans and Other Primates: A New Synthesis

Herman Pontzer...

An Evolutionary and Life-History Perspective on Osteoporosis

Felicia C. Madimenos

Disturbance, Complexity, Scale: New Approaches to the Study of

Human-Environment Interactions

Rebecca Bliege Bird

Fallback Foods, Optimal Diets, and Nutritional Targets: Primate

Responses to Varying Food Availability and Quality

Joanna E. Lambert and Fessica M. Rotbman 
Resource Transfers and Human Life-History Evolution

fames Holland Fones

An Evolutionary Anthropological Perspective on Modern

Human Origins

Curtis W. Marean

\section{Anthropology of Language and Communicative Practices}

How Postindustrial Families Talk

Elinor Ochs and Tamar Kremer-Sadlik

Chronotopes, Scales, and Complexity in the Study of Language

in Society

Fan Blommaert

Linguistic Relativity from Reference to Agency

N.7. Enfield

Politics of Translation

Susan Gal....

Breached Initiations: Sociopolitical Resources and Conflicts in Emergent Adulthood Norma Mendoza-Denton and Aomar Boum

Embodiment in Human Communication

Fürgen Streeck

The Pragmatics of Qualia in Practice

Nicholas Harkness

\section{Sociocultural Anthropology}

Virtuality

Bonnie Nardi

Anthropology and Heritage Regimes

Haidy Geismar

Urban Political Ecology

Anne Rademacher

Environmental Anthropology: Systemic Perspectives

Yancey Orr, 7. Stephen Lansing, and Michael R. Dove

The Anthropology of Life After AIDS: Epistemological Continuities

in the Age of Antiretroviral Treatment

Eileen Moyer....

Anthropology of Aging and Care

Elana D. Buch 
Anthropology of Ontologies

Eduardo Kohn

Oil and Anthropology

Douglas Rogers...

The Post-Cold War Anthropology of Central America

Jennifer L. Burrell and Ellen Moodie

Risks of Citizenship and Fault Lines of Survival

Adriana Petryna and Karolina Follis

Siberia

Piers Vitebsky and Anatoly Alekseyev

Of What Does Self-Knowing Consist? Perspectives from Bangladesh and Pakistan

Naveeda Khan

Addiction in the Making

William Garriott and Eugene Raikbel

Waste and Waste Management

Joshua Reno

\section{Theme: Resources}

Virtuality

Bonnie Nardi

Pleistocene Overkill and North American Mammalian Extinctions

David 7. Meltzer

Urban Political Ecology

Anne Rademacher

Environmental Anthropology: Systemic Perspectives

Yancey Orr, 7. Stephen Lansing, and Michael R. Dove ...

Energy Expenditure in Humans and Other Primates: A New Synthesis

Herman Pontzer.

Disturbance, Complexity, Scale: New Approaches to the Study of

Human-Environment Interactions

Rebecca Bliege Bird

Anthropology of Aging and Care

Elana D. Buch

Breached Initiations: Sociopolitical Resources and Conflicts in

Emergent Adulthood

Norma Mendoza-Denton and Aomar Boum 
Recent Developments in High-Density Survey and Measurement (HDSM) for Archaeology: Implications for Practice and Theory Rachel Opitz and W. Fred Limp

Oil and Anthropology

Douglas Rogers

Resource Transfers and Human Life-History Evolution

fames Holland Fones

Waste and Waste Management

Joshua Reno

\section{Indexes}

Cumulative Index of Contributing Authors, Volumes 35-44 _.................... 591

Cumulative Index of Chapter Titles, Volumes 35-44 ........................... 595

\section{Errata}

An online log of corrections to Annual Review of Anthropology articles may be found at http://www.annualreviews.org/errata/anthro 